\section{International Scientific Journal Theoretical \& Applied Science}

p-ISSN: 2308-4944 (print)

e-ISSN: 2409-0085 (online)

Year: 2015

Issue: 11

Volume: 31

Published: 30.11 .2015

http://T-Science.org
Inna Aleksandrovna Serebryanik

Associate Professor of the Department of World economy, Candidate of technical sciences, Irkutsk

National Research Technical University nasamolet@yandex.ru

Darya Maksimovna Zolotuhina

Student, Irkutsk National Research Technical University

SECTION 31. Economic research, finance, innovation, risk management.

\title{
GLOBAL COFFEE MARKET: BASIC CONCEPTS
}

Abstract: Analyzed the main characteristics of the coffee, as a commodity of international trade. Shows the factors of pricing. It depicts the main trends of coffee consumption.

Key words: coffee, arabica, robusta, specialty, volatility.

Language: Russian

Citation: Serebryanik IA, Zolotuhina DM (2015) GLOBAL COFFEE MARKET: BASIC CONCEPTS. ISJ Theoretical \& Applied Science 11 (31): 23-25.

Soi: http://s-o-i.org/1.1/TAS-11-31-5 Doi: crossef http://dx.doi.org/10.15863/TAS.2015.11.31.5

\section{МИРОВОЙ РЫНОК КОФЕ: БАЗОВЫЕ ПОНЯТИЯ}

Аннотация: Проанализированы основнье характеристики кофе, как товара международной торговли. Показаны факторы иенообразования. Показаны основные тенденции потребления кофе.

Ключевые слова: кофе, арабика, робуста, спешелти, волатильность.

В мировой торговли кофе занимает вторую позицию, уступая пальму первенства лишь нефти. Кофе - второй по популярности напиток после воды. Каждый день человечество выпивает более 2 млрд. чашек кофе. Объемы потребления молока зависят от объемов потребления кофе.
Более 20 млн. человек в мире заняты выращиванием и торговлей кофе. При этом 90\% производства кофе сосредоточено в развивающихся странах. Страны лидеры - это Бразилия, Вьетнам, Индонезия и Колумбия (см.рисунок 1).

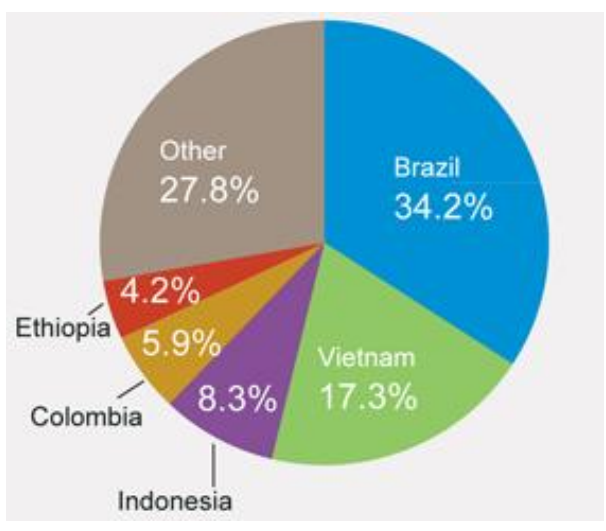

Рисунок 1 - Страны-лидеры по производству кофе, 2014 г. [1]

Страны-лидеры по потреблению кофе представлены на рисунке 2. 


\begin{tabular}{l|lrl|l|ll} 
& ISRA (India) & $=\mathbf{1 . 3 4 4}$ & SIS (USA) & $=\mathbf{0 . 9 1 2}$ & ICV (Poland) & $=\mathbf{6 . 6 3 0}$ \\
Impact Factor: & ISI (Dubai, UAE) $=\mathbf{0 . 8 2 9}$ & PUHU (Russia) $=\mathbf{0 . 1 7 9}$ & PIF (India) & $=\mathbf{1 . 9 4 0}$ \\
& GIF (Australia) & $\mathbf{0 . 5 6 4}$ & ESJI (KZ) & $=\mathbf{1 . 0 4 2}$ & & \\
& JIF & $=\mathbf{1 . 5 0 0}$ & SJIF (Morocco) $=\mathbf{2 . 0 3 1}$ & &
\end{tabular}

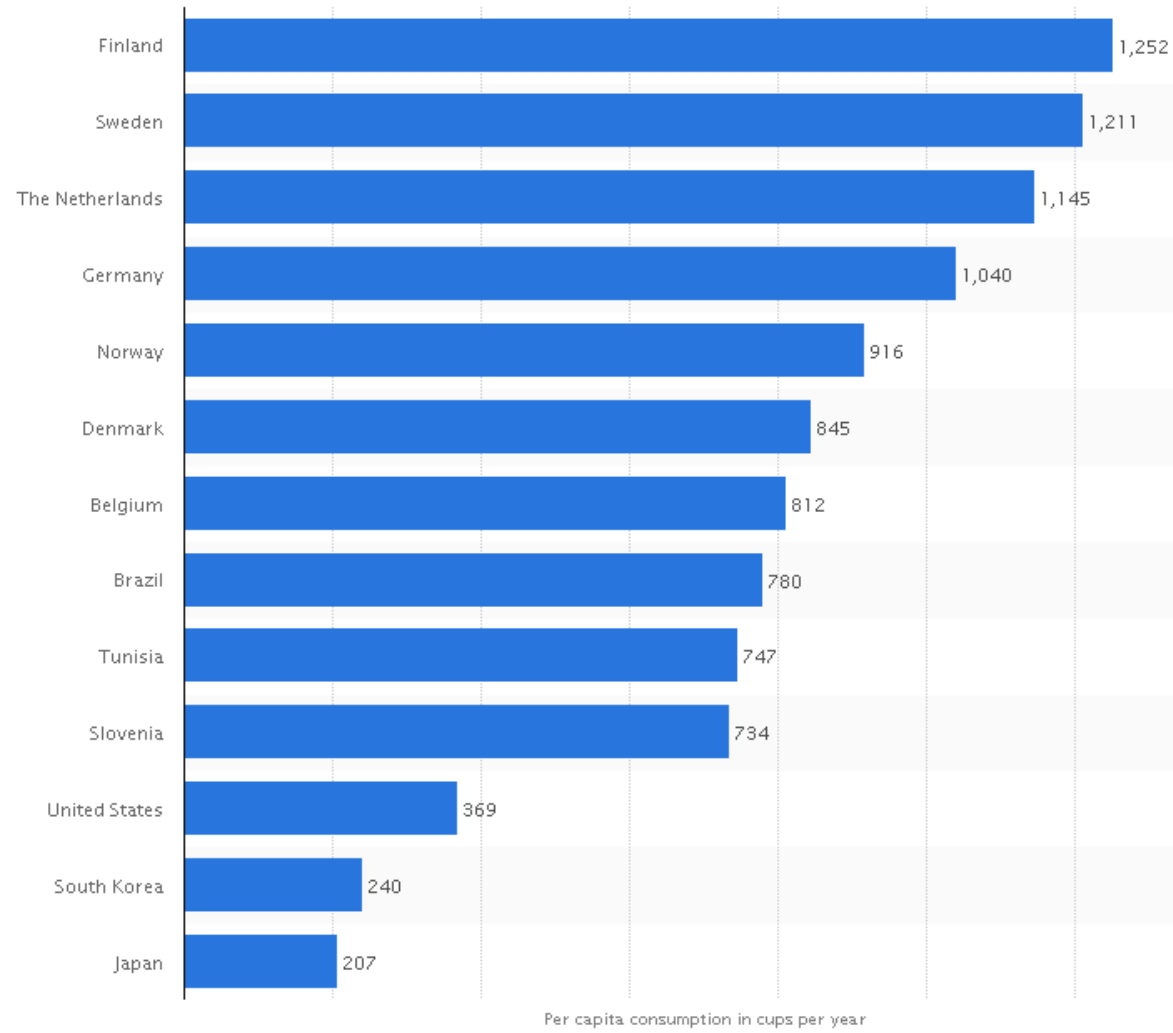

Рисунок 2 - Страны-лидеры по потреблению кофе, 2014 г. [3]

Кофе - биржевой товар. Торгуются зеленые зерна кофе. Зеленые зерна способны храниться очень долго, чего нельзя сказать об обжаренном кофе и тем более, молотом. Торговыми считаются два сорта кофе - арабика и робуста. Арабика - это высокогорный кофе. Он отличается более изысканным вкусом, нежели робуста. Также в арабике меньше содержание кофеина. Робуста - кофе быстрого созревания, растет на небольших высотах, не отличается ни изысканным вкусом, ни приятным запахом. Однако робуста - крепкий кофе, потому его охотно используют, например, в эспрессо-смесях. На основе робусты также производят большую часть растворимого кофе.

Объемы производства арабики и робусты за последние годы представлены на рисунке 3.

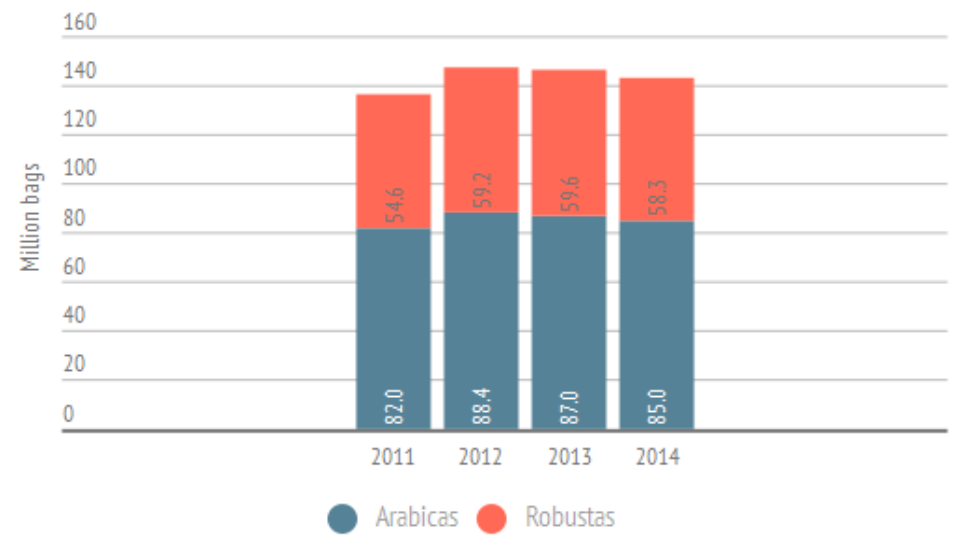

Рисунок 3 - Объемы производства арабики и робусты, 2011-2014 гг. [2]

Некоторой проблемой кофейного рынка является то, что нет единой градации зерен кофе. Каждая страна по-своему классифицирует зерно.
Можно выделить основные характеристики, влияющие на вкус кофе и, в конечном счете, на цену продукта: 


\begin{tabular}{|c|c|c|c|c|c|c|}
\hline Impact Factor: & $\begin{array}{l}\text { ISRA (India) } \\
\text { ISI (Dubai, UAE } \\
\text { GIF (Australia) } \\
\text { JIF }\end{array}$ & $\begin{array}{r}=1.344 \\
=\mathbf{0 . 8 2 9} \\
=0.564 \\
=1.500\end{array}$ & $\begin{array}{l}\text { SIS (USA) } \\
\text { PИHЦ (Russia) } \\
\text { ESJI (KZ) } \\
\text { SJIF (Morocco) }\end{array}$ & $\begin{array}{l}=0.912 \\
=0.179 \\
=1.042 \\
=\mathbf{2 . 0 3 1}\end{array}$ & $\begin{array}{l}\text { ICV (Poland) } \\
\text { PIF (India) }\end{array}$ & $\begin{array}{l}=6.630 \\
=1.940\end{array}$ \\
\hline
\end{tabular}

1.Регион произрастания;

2. Высота произрастания;

3.Плотность (твердость) зерна;

4.Способ обработки зерна;

5. И другие.

Различают два вида кофейного зерна коммерческое и спешелти (specialty) [8]. Кофе дает в год четыре урожая. Три из них - обычный кофе, который обычно не успел вызреть между сезонами дождей. Такой кофе считают массовым - коммерческим. Четвертый урожай уникальный. Его собирают вручную тремя подходами через 10 дней. Этот урожай успевает получить уникальные характеристики, и именно его относят к категории спешелти. Надо заметить, что это только арабика, которая выросла на высоте свыше 1000 м. Спешелти $100 \%$ фермерский продукт и цена на него достаточно высока.

Сделки по покупке-продаже кофе проходят на двух биржах - в Нью-Йорке (арабика) и Лондоне (робуста). Существенные запасы кофе хранятся в портовых городах Европы Роттердам, Амстердам, Гамбург, Бремен, Лондон, Триест.

Объемы экспорта и импорта кофе традиционно считают мешками. Вес одного мешка - 60 кг.
Цена на кофе считается чрезвычайно волатильной [7], в силу непредсказуемости рынка. То бразильский урожай замерзнет, то Вьетнам выйдет на рынок с огромными объемами дешевого кофе. Рынок кофе - это рынком погоды. Даже угроза заморозков может вызвать существенный скачок цен фьючерсных цен. Многие из стран-производителей кофе не отличаются стабильным политическим и экономическим развитием, и этот фактор, конечно, влияет на цену.

Торговля кофе проходит в двух вариантах: 1. FOB (free on board);

2.CIF (cost, insurance and freight).

Рынок кофе регулируется с 1962 года. В этом году было подписано Международное соглашение по кофе, которое ратифицировали, как страны-производители, так и страныпотребители кофе. За соблюдением соглашения следит International Coffee Organization (ICO) Международная Организация по Кофе. Основной регулятор ICO - установление экспортных квот.

\section{References:}

1. (2015) International Coffee Organization Blog. Available: http://icocoffeeorg.tumblr.com/ (Accessed: 1.11.2015).

2. (2015) International Coffee Organization. Available: http://www.ico.org (Accessed: 1.11.2015)

3. (2015) The Statistics Portal. Available: http://www.statista.com (Accessed: 1.11.2015).

4. Illy E (2002) The complexity of coffee. //Scientific American - June - 2002: 86-91.

5. Furta O (2009) Biblija kofe: ot rostka do chashki /Ol'ga Furta. - Moscow: Jeksmo, 2009. $-288 \mathrm{p}$.

6. Pendergrast M (2015) Uncommon Grounds: The History of Coffee and How It Transformed Our World. // Basic Books- 554 p.
7. (2015) Price volatility and production shortfalls: what's happening in the coffee market? Available: http://researchcenter.amundi.com/index.php/page/Article/201 5/02/Price-volatility-and-production-shortfallswhat-s-happening-in-the-coffeemarket?search=true (Accessed: 1.11.2015).

8. Robert G. Hewitt (1872) Coffee. Its history. Cultivation. Uses. - New-York: D. Appleton and company, 1872.

9. Sara Perry (1991) The complete coffee book. //Chronicle Books, 1991. 96 p.

10. Shamba N (2002) Kofe. //izd.Zhigul'skogo. Moscow, 2002. 128 p. 